\title{
Xenohormesis: Applying Evolutionary Principles to Contemporary Health Issues
}

\author{
Shelley Suter and Mark Lucock* \\ School of Environmental \& Life Sciences, University of Newcastle, Ourimbah, NSW 2258, Australia
}

\begin{abstract}
The ability of plants to exert health benefits beyond antioxidant and micronutrient capacity introduces a gap in scientific understanding. The xenohormesis hypothesis aims to fill this gap, proposing that an evolutionary adaptation of enzyme and receptor pathways allow us to react to information that plants provide about the environment, offering a distinct survival advantage. The concept suggests that phytochemicals produced by plants under stress are able to activate longevity pathways in other organisms when consumed. The same pathways activated by calorie restriction, the highly conserved sirtuin enzymes and cellular homeostasis mechanisms provide an exciting perspective for treating chronic conditions related to excessive consumption. Harnessing the biological activity associated with the xenohormesis paradigm could provide a simple and achievable therapeutic alternative, although it needs to be considered within the confounding framework. The objective of this paper is to provide an update on the role of xenohormesis within nutritional medicine and to discuss the impact of modern food supply and consumption practices on evolutionary processes.
\end{abstract}

\section{Introduction}

Hormesis is the biological process where a low dose exposure to a toxin or environmental condition, which would otherwise be damaging at a higher dose, induces an adaptive response that is actually beneficial. ${ }^{1}$ It is a concept embedded in evolutionary theory, and essentially it supports the idea that what does not kill us makes us stronger. The xenohormesis hypothesis, first coined by Howitz and Sinclair, explains how stressed plants and autotrophs produce compounds that offer survival benefits to animals that consume them. ${ }^{2,3}$ It specifically proposes that the majority of health benefits from plant consumption come not only from their known antioxidant and micronutrient properties, but also from an evolutionary adaptation of enzyme and receptor pathways. According to the hypothesis, mammals and fungi have the ability to utilize and react to information plants provide about the environment, offering a distinct selective advantage. ${ }^{3}$

The molecular mechanisms underlying the hypothesis are not

Keywords: Xenohormesis; Polyphenols; Phytochemicals; Nutritional medicine; Resveratrol; Stress response; Sirtuin.

Abbreviations: CVD, cardiovascular disease; ER, endoplasmic reticulum; NIDDM, non-insulin dependent diabetes mellitus; PERM, proteasome, endoplasmic reticulum and mitochondria; ROS, reactive oxygen species; UPR, unfolded protein response; $\mathrm{UPR}^{\mathrm{MT}}$, mitochondrial unfolded protein response.

Received: July 21, 2017; Revised: October 26, 2017; Accepted: November 06, 2017 *Correspondence to: Mark Lucock, School of Environmental \& Life Sciences, University of Newcastle, PO Box 127, Brush Rd, Ourimbah, NSW 2258, Australia. Tel: +61 24348 4109, Fax: +61 24348 4145, E-mail: Mark.Lucock@newcastle.edu.au How to cite this article: Suter S, Lucock M. Xenohormesis: Applying Evolutionary Principles to Contemporary Health Issues. Exploratory Research and Hypothesis in Medicine 2017;2(4):79-85. doi: 10.14218/ERHM.2017.00023. yet fully understood; however, the philosophical perspective provides insight on stress responses and their biochemical purpose. Stress is a universal state experienced by all living organisms in response to their environment. Plants are particularly vulnerable because they are unable to remove themselves from danger and have highly developed coping mechanisms to ensure survival. Plants experiencing mild stress in the form of severe temperature, dehydration, nutrient deprivation, sun exposure, toxins and predators produce a variety of protective compounds or secondary metabolites known as phytochemicals. These allow plants to overcome continuous and temporary threats to their survival; such phytochemicals act as UV filters, antibiotics, insecticides and fungicides, while also defending against herbivores, competitive plant species and pollutants. ${ }^{4}$ When consumed, these bioactive plant molecules have the ability to induce and up-regulate specific biological pathways associated with endurance, longevity and disease resistance in animals. Unsurprisingly, survival, reproductive ability and natural selection favors those that activate longevity and cellular defensive pathways, and so facilitate the natural cycle of plant stress and conferred resistance in animals.

The success of an evolutionary process partially relies on the concept that environmental exposure represents a relevant and significant threat to survival. Considering the increasing occurrence of contemporary health conditions relating to affluence and excessive consumption, it is possible to draw a link between dietary habits that do not reflect physiological needs (and agricultural practices that do not reflect a balanced environment) and the interruption of survival processes. The xenohormesis hypothesis can be used not only as a way of identifying mechanisms that aid in our understanding of disease etiology but also as an exciting modern concept embracing nutritional medicine, targeting treatment and 
prevention. This paper aims to review the current understanding regarding xenohormesis and associated biological pathways as well as the realistic application of related compounds in response to contemporary health problems.

\section{Evolution of the human diet and contemporary health issues}

Throughout the human lineage, consumption of plant and animal food products has changed in response to environmental and lifestyle factors. The xenohormesis hypothesis suggests that non-nutrient plant molecules assist in human stress resistance and survival during harsh conditions; however, it is unlikely that this activity alone dictated survival. Energy dense animal food sources and their associated stress signals played a central role in evolutionary development and natural selection. ${ }^{5}$ Humans have a long and seemingly successful history of meat consumption, with the use of animal food products dating back at least 5 million years. ${ }^{6}$ In modern society however, excessive meat consumption, in combination with other high-energy foods and a sedentary lifestyle, is associated with a growing list of chronic conditions. ${ }^{6}$ A recent population-based cohort study showed an increased risk of mortality from nine different causes directly linked with red meat and processed meat consumption, ${ }^{7}$ while excessive sugar consumption plays a key role in metabolic disease by altered lipid and carbohydrate metabolism, positive energy balance and weight gain. ${ }^{8}$ These results are important to consider in the context of xenohormesis because they identify problems arising from nutritional practices that do not reflect physiological needs in our contemporary environment.

It is difficult to predict the extent to which dietary behaviors affect health; however, the etiology of most conditions is in some way related to an individual's past or present nutritional status. Non-insulin dependent diabetes mellitus (NIDDM) and cardiovascular disease (CVD) are often referred to as diseases of affluence, where prevalence rises with economic development. While affluence is no longer considered the major factor it once was, these diet-related chronic diseases impose a significant healthcare burden. In 2010, dietary risk factors such as low fruit intake, in combination with excess energy and physical inactivity were estimated to account for $10 \%$ of global disability and years of life lost. ${ }^{9}$ Therefore, it is possible to associate contemporary health issues with inappropriate biological stress and environmental disconnection. Treating diet-related disease with dietary intervention is not a novel concept; however, considering the complex evolution of the human diet and the risks associated with contemporary food choices, a deeper understanding of xenohormesis could provide a specific direction for nutritional intervention.

\section{Calorie restriction}

Calorie excess is a primary risk factor in a variety of modern health problems; therefore, it is not surprising that calorie restriction is associated with increased lifespan and improved health. First identified in rats over 75 years ago, ${ }^{10}$ the relationship between fasting and longevity has been observed in a variety of organisms, including yeast, flies, rodents and monkeys. ${ }^{11,12}$ While the exact mechanism remains relatively unknown, various relevant metabolic pathways have been identified. ${ }^{13}$ Calorie restriction, but not starvation, initiates mild stress in the deprived organism and activates pathways related to increased metabolic efficacy and protection from cellular damage. ${ }^{13}$ These pathways are the result of a highly conserved evolutionary response, where improved health from fasting ensures survival in times of restriction and thus the ability to reproduce when suitable conditions return. In a time where many chronic conditions are associated with obesity, the concept that calorie restriction could improve population health status seems obvious yet remarkably difficult to put into practice. A key point here is that plant compounds are known to activate the same longevity pathways associated with calorie restriction when consumed. ${ }^{14}$

\section{Xenohormetic pathways}

Many non-nutritional dietary components activate stress responses and homeostasis mechanisms in animals. Polyphenols are a group of phytochemicals closely associated with plant stress and secondary resistance in animals. Bioactive polyphenols are known to have antioxidant and anti-inflammatory properties, and have been directly linked to reduced mortality rates in humans. ${ }^{15,16}$ One of the most promising and well-researched xenohormetic polyphenols is resveratrol, a stilbene commonly known for its presence in red wine.

Resveratrol activates the same pathways as calorie restriction, with early research showing the compound was able to activate sirtuin (SIRT2) enzymes in the yeast strain Saccharomyces cerevisiae, resulting in improved DNA stability and a dramatic $70 \%$ increase in lifespan. ${ }^{17}$ This observation essentially formed the foundations of the xenohormesis hypothesis, sparking interest in phytochemically activated enzyme/receptor pathways and their origin. The mammalian sirtuin homologs, a group of $7 \mathrm{NAD}^{+}$dependent histone deacetylases (SIRT 1-7), act on a variety of physiological processes including metabolism, apoptosis, DNA repair and DNA transcription. ${ }^{18}$ Due to the synthesis of resveratrol in response to stress, grapes grown in undesirably cool environments, at high elevation or in alkaline soil produce the best wine in relation to taste and health. ${ }^{19}$ It is because of resveratrol and other polyphenolic compounds that mild to moderate wine drinking has been linked to cancer protection and reduced cardiovascular disease, as well to slowing of neurodegenerative conditions. ${ }^{20-23}$ While antioxidant activity is partially responsible for resveratrol's protective action, it is also thought to be the result of a highly adaptive stress response and various signaling pathways activated by SIRT1 enzymes in mammals.

Other biological pathways involved in stress response and survival mechanisms should be considered alongside or within the xenohormesis paradigm. The proteasome, endoplasmic reticulum and mitochondria (PERM) hypothesis aims to explain how xenobiotic compounds, including trace metals and phytochemicals, exert beneficial effects via homeostatic mechanisms. ${ }^{24}$ The hypothesis explains stress response on a cellular level, where proteasomes, the endoplasmic reticulum (ER), mitochondria and peroxisomes, collectively form a functional structure labeled the proterome. The proterome works to regulate cell apoptosis or autophagy under oxidative stress by mechanisms of altered calcium homeostasis, mitochondrial polarization and chaotic oscillation. It is thought that reactive oxygen species (ROS) produced by exposure to phytochemicals and xenobiotic compounds act as signaling molecules that trigger ER stress and subsequent proterome formation. While extended or excessive exposure to ROS leads to protein, lipid and nucleic acid degradation, low amounts exert therapeutic like effects by regulation of cell signaling cascades..$^{25}$ The outcome is cell conservation or death, and the resulting pathway ultimately supports survival of the remaining living cells.

ER stress and mitochondrial stress occur in response to genetic and environmental factors. Cells under physiological stress pro- 


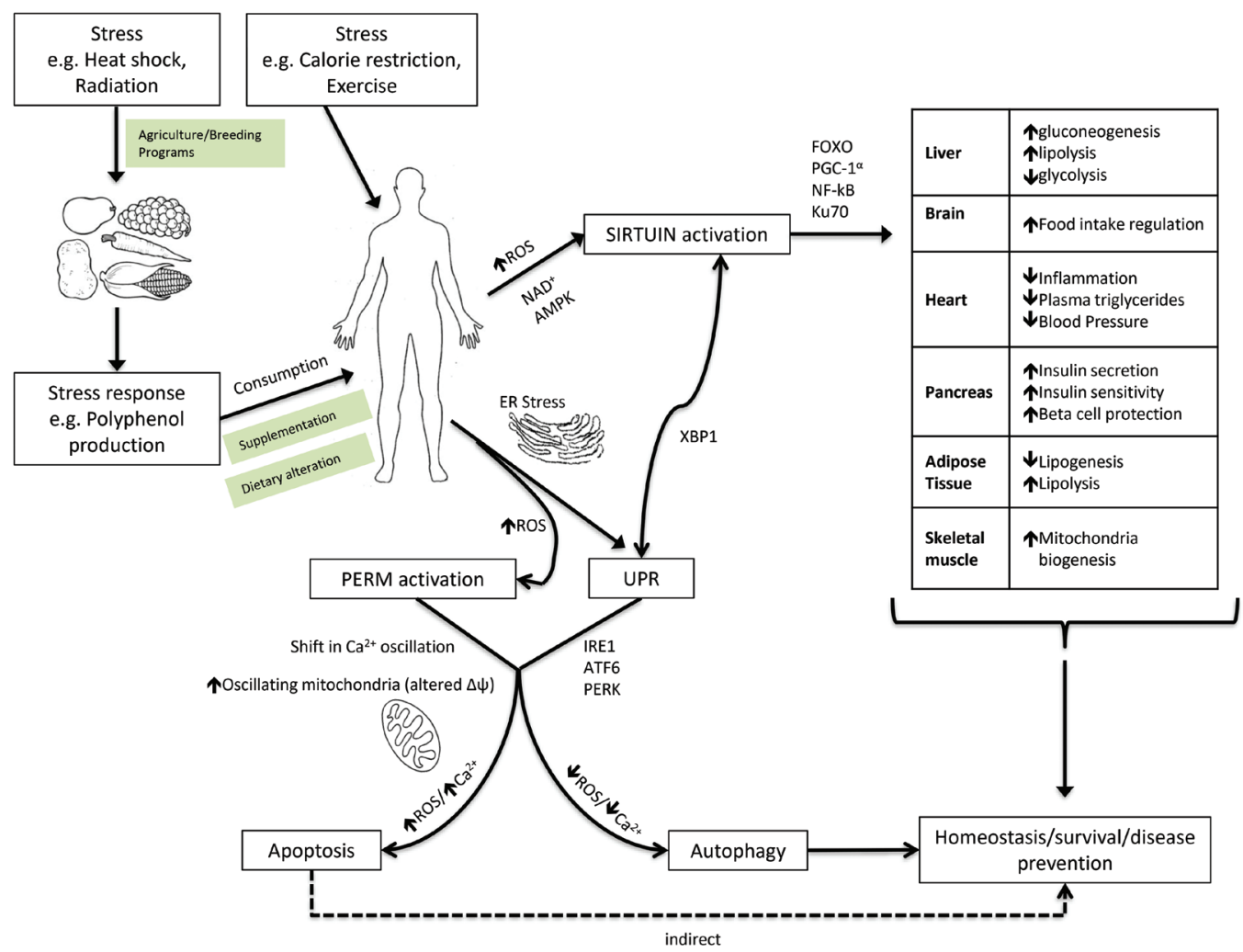

Fig. 1. Mechanism of xenohormesis from plant stress to SIRT1 activation and cellular homeostasis. Mild stress and the consumption of plant stress compounds activate SIRT1 enzymes and subsequent pathways associated with increased stress resistance and survival. ${ }^{3}$ Biological targets of sirtuin enzymes include the liver, brain, heart, pancreas, adipose tissue and skeletal muscle, conferring a diverse range of health benefits. ${ }^{18}$ In pursuit of cellular homeostasis and survival after mild physiological stress, the ER UPR is up-regulated. ${ }^{31,32}$ The ROS in response to mild ER stress serves as a signal to the proposed PERM mechanism, further ensuring homeostasis and organism survival via cell conservation or cell death. ${ }^{24}$ Therapeutic intervention could be achieved by agricultural, dietary or supplementation intervention. Abbreviations: AMPK, adenosine monophosphate-activated protein kinase; ATF6, activating transcription factor 6; ER, endoplasmic reticulum; FoxO, forkhead box class O; IRE1, inositol-requiring enzyme 1; NAD, nicotinamide adenine dinucleotide; NF-KB, nuclear factor-KB; PERK, protein kinase-like ER kinase; PERM: proteasome, endoplasmic reticulum and mitochondria; PGC- ${ }^{\alpha}$, peroxisome proliferator-activated receptor gamma coactivator-1 ${ }^{\alpha}$; ROS: reactive oxygen species; UPR: unfolded protein responses; XBP1, X-box binding protein 1.

duce unfolded proteins, the ER's primary role is to ensure only folded proteins exit the cell. The unfolded protein response (UPR) occurs as a homeostatic mechanism of the ER and its purpose is to monitor protein-folding capacity and ER abundance to ensure quality and control of protein transcription. ${ }^{26,27}$ Similarly, the mitochondrial stress response, coined the mitochondrial unfolded protein response (UPR ${ }^{\mathrm{MT}}$ ), is a quality control system comprised of signaling pathways to the nucleus and ER. Damaged proteins or a disrupted membrane potential in response to ROS accumulation activate the UPR ${ }^{\mathrm{MT}}$ in pursuit of mitochondrial homeostasis. ${ }^{28}$

Mitochondria and ER communication is essential for appropriate apoptosis and autophagy; dysfunction is directly linked to the etiology of many chronic diseases, including the development of NIDDM and CVD. ${ }^{29,30}$ For example, in response to excessive consumption and obesity, there is an increased demand on pancreatic beta cells for insulin production, causing cellular stress and protein mutation. ${ }^{31}$ ER hormesis can trigger and up-regulate the UPR, meaning mild stress provides protection in certain disease models and is considered a plausible therapeutic target. ${ }^{32}$ It is also proposed that sirtuin activation is linked to the UPR, where up-regulation of sirtuins and subsequent deacetylation of the XPB1 protein controls UPR signaling and further prevents cellular dysfunction. ${ }^{33}$

The PERM hypothesis, ER and mitochondrial stress responses, can be considered alongside the xenohormesis hypothesis and sirtuin activation to understand cellular stress resistance and its implication on human health. Figure $1^{3,18,24,31,32}$ summarizes the occurrence of sirtuin activation, cellular homeostasis mechanisms and their relevant biological pathways, and identifies areas susceptible to therapeutic intervention.

\section{Xenohormesis and the modern diet}

Xenohormetic awareness raises important questions about the food supply chain; the way we eat, source and respond to our food is continuously changing in response to a growing population and climate change. It is well known that modern agricultural practices aim for large yields and uniformed produce in order to optimize financial profit. Crops are provided with ideal conditions for growth in the form of environmental or chemical protection, removing any form of stress that could inhibit or alter the final product. Many studies have identified composition differences between organic and conventional plants and while results are often conflicting with regard to nutritional value, there is a general consensus that conventional inorganic practices produce larger yields and fewer stress compounds. ${ }^{34-36}$ Previous reviews on xenohormesis have raised concern regarding the increasing popularity of mono-cropping and the subsequent loss of nutritional benefit. ${ }^{37}$ While growth and har- 
Table 1. Phytochemical compounds associated with hormetic pathways and a selection of clinical evidence supporting their therapeutic potential

\begin{tabular}{|c|c|c|c|}
\hline Compound & Classification & Food Source & Therapeutic Potential \\
\hline Sulphoraphane & $\begin{array}{l}\text { Organosulphur } \\
\text { Isothiocyanate }\end{array}$ & $\begin{array}{l}\text { Cruciferous vegetables (broccoli, } \\
\text { brussels sprouts, cabbage, kale) }\end{array}$ & $\begin{array}{l}\text { Improved insulin resistance in NIDDM patients }{ }^{47} \\
\text { Defence against oxidative stress and Cardiovascular disease }{ }^{48}\end{array}$ \\
\hline Catechins & Flavanol & $\begin{array}{l}\text { Green tea, dark chocolate, } \\
\text { red wine, apples }\end{array}$ & $\begin{array}{l}\text { Reduce body fat and low-density lipoprotein in healthy men }{ }^{49} \\
\text { Modulation of oxidative stress in subjects with heart failure and } \\
\text { type } 2 \text { diabetes }{ }^{50}\end{array}$ \\
\hline Curcumin & Diarylheptanoid & Turmeric & $\begin{array}{l}\text { Prevention of NIDDM in a pre-diabetic population and improved } \\
\text { function of beta cells } s^{51} \\
\text { Cholesterol improvement in subjects with metabolic syndrome }\end{array}$ \\
\hline Resveratrol & Stilbene & $\begin{array}{l}\text { Grapes, peanuts, blueberries, } \\
\text { cocoa, dark chocolate }\end{array}$ & $\begin{array}{l}\text { Exercise mimetic activity, SIRT1 activation and improved energy } \\
\text { expenditure in patients with NIDDM } \\
\text { Reduced lipoprotein particle production in patients with } \\
\text { hypertriglyceridemia } 54\end{array}$ \\
\hline Lignan & Phytoestrogen & $\begin{array}{l}\text { Flaxseeds, whole grains, } \\
\text { sesame seeds }\end{array}$ & $\begin{array}{l}\text { High lignan intake can decrease oxidized low-density lipoprotein } \\
\text { in healthy men and women } \\
\text { Antihypertensive activity associated with changes in diastolic } \\
\text { blood pressure in patients with cardiovascular disease }\end{array}$ \\
\hline Quercetin & Flavonol & $\begin{array}{l}\text { Cherries, berries, tomatoes, } \\
\text { apples, peppers, red } \\
\text { wine, citrus fruits }\end{array}$ & $\begin{array}{l}\text { Improved glycemic and insulin response in NIDDM patients }{ }^{57} \\
\text { Combined green tea, resveratrol and quercetin supplementation } \\
\text { reduced diastolic pressure and improved blood pressure in } \\
\text { hypertensive subjects }\end{array}$ \\
\hline
\end{tabular}

Abbreviation: NIDDM, non-insulin dependent diabetes mellitus.

vesting techniques that remove plant stress essentially eradicate the traditional application of xenohormesis, it could be argued that this is simply an evolutionary reflection of a time where the environment does not represent an immediate threat. Despite this, and in response to increasing concern, a growing consumer demand for higher quality fruit and vegetables has promoted the exploration of breeding programs focused on improving the nutritional qualities of fresh produce.

Applying mild stress in the form of high light, heat shock and chilling shock can increase the concentration of phenolic compounds in lettuce without inhibiting overall growth or yield, ${ }^{38}$ while the cultivation period and phytochemical concentration in broccoli can be increased by low radiation exposure under controlled temperature. ${ }^{39}$ The concept provides an opportunity for population level nutritional intervention; however, it is not without practicality issues. Most polyphenols and bioactive compounds are bitter or astringent; therefore, increasing nutritional value is either limited or achieved only by sacrificing sensory quality. ${ }^{40}$ While nature's regulation of polyphenol intake presents limitations for the deliberate application of xenohormesis, this remains an exciting area of food and nutritional science and provides scientists with the ability to generate plants that could address diet-related chronic disease and possibly global scale health issues. ${ }^{41,42}$

\section{Xenohormesis and nutritional medicine}

Xenohormesis, via nutrition, is associated with survival, unintentional disease prevention and general wellbeing. Phytochemicals have a secure place in the nutraceutical market; however, their suitability for prevention of chronic disease remains largely undefined. Plant compounds that activate longevity pathways and cellular homeostasis mechanisms have successfully demonstrated medicinal activity for NIDDM, CVD, hypertension and other conditions associated with aging and diet. ${ }^{43,44}$ However, despite obvious therapeutic potential and commonly supported non-toxicity, ${ }^{45,46}$ many factors have prevented definitive recommendations regarding medicinal use at this time. It is important to note that plants interact with many biological pathways and demonstrate diverse therapeutic activity, which means their physiological effect can be inconsistent and altered by many variables. Table $1^{47-58}$ outlines a selection of clinical evidence supporting the therapeutic use of certain phytochemical compounds.

It is thought that dietary polyphenols can provide relief to subjects with NIDDM by obvious anti-inflammatory and antioxidant capacity, but also by offering protection to pancreatic beta cells against glucose toxicity. ${ }^{59}$ Resveratrol has been widely studied for its ability to interact with insulin-regulated blood glucose pathways. Use of the polyphenol was shown to extend the lifespan and exert a wide range of health benefits on overweight mice subjected to a high-calorie diet ${ }^{60}$; however, the same meaningful results are yet to be achieved in subjects of normal weight. ${ }^{61}$ Another animal study has confirmed the context-dependent activity of resveratrol, with variables such as sex, diet and metabolic condition directly influencing the results. ${ }^{62}$ Human trials have also shown that beneficial activity is dictated by dosage, length of exposure and the patient's health status. Twenty-six weeks of resveratrol intake, in otherwise healthy overweight subjects, was able to improve memory and brain function in addition to improved glucose metabolism, ${ }^{63}$ which is supported by another study reporting beneficial effects on blood glucose levels in overweight participants. ${ }^{64}$ In contrast however, 8 weeks of red wine polyphenol supplementation in obese volunteers did not improve insulin sensitivity, and when trialed on healthy non-obese patients, resveratrol was shown to have little to no effect. ${ }^{65,66}$ Based on current knowledge, resveratrol activity might be more beneficial when administered as a smaller dose over a long period of time. Furthermore, its therapeutic affect appears to favor those with already compromised health, which is significant when considering prevention of NIDDM in overweight subjects.

Many plant compounds have demonstrated beneficial cardio- 
vascular effects, including antioxidant, antithrombotic and antiinflammatory properties. ${ }^{67}$ Phytochemicals play a multi-faceted role in the treatment and prevention of CVD; alteration of endothelial cell function, blood lipid profile and blood pressure are areas susceptible to phytochemical therapy. Human trials have shown that polyphenols can significantly reduce fasting and postprandial plasma triglyceride concentrations in obese metabolically compromised subjects. ${ }^{68}$ Furthermore, participants at high CVD risk, who consumed high amounts of stilbene polyphenols and lignin from a Mediterranean diet, demonstrated a reduced risk of overall mortality after 5 years of dietary intervention. ${ }^{69}$ Interestingly, grape-seed polyphenol supplementation in hypertensive adults did not significantly influence blood pressure measurements and combined polyphenol and vitamin C supplementation over 6 weeks negatively increased blood pressure variation, suggesting combined therapy could be detrimental. ${ }^{70}$ While the benefits of polyphenol intake on CVD risk is evident, it remains unclear whether a typical intake of polyphenol-rich foods offers cardio-protection. ${ }^{71,72}$

\section{Limitations}

The xenohormesis hypothesis represents a concept with evolutionary biology at the heart of the paradigm; however, purposeful application of the concept presents limitations. Current research suggests resveratrol treatment is only beneficial in certain population groups, with many studies having focused on overweight, metabolically-challenged or elderly subjects. While it is ethically and practically difficult to establish a causal connection between plant compounds and the extension of human longevity, the relevance of extrapolation from animal and in vitro studies remains unknown. From a philosophical perspective, exploitation of evolutionary processes could be counterproductive, and limitations regarding suitable use could be a reflection of this. Previous reviews have highlighted the inconsistency of phytochemical bioavailability in humans and how medicinal qualities are difficult to reproduce due to composition variation from one plant to the next. ${ }^{37}$ Additionally, despite the fact that resveratrol and other polyphenols are found in many foods, in reality they are not very abundant in a normal diet. While the recommended daily dosage is varied and supplements range from $2 \mathrm{mg}$ up to $500 \mathrm{mg}$, the average resveratrol and resveratrol-derivative intake in certain wine-drinking population groups is just $100 \mu \mathrm{g} /$ day and $933 \mu \mathrm{g}$ /day respectively. ${ }^{73}$ Studies concerning appropriate dosage, where smaller amounts appear to be more beneficial, ${ }^{74,75}$ further reiterate the idea that polyphenol activity is part of a wider, context-dependent, biological occurrence.

\section{Perspective}

Xenohormesis and its medicinal scope is a broad concept, difficult to comprehend on a large scale. In order to gain a wider understanding and to overcome the limitations discussed previously, research should be focused on smaller, independent areas. Further identification of hormetic compounds and the food sources that provide them is an essential part of this process. Agricultural factors restricting the traditional application of xenohormesis should be identified along with advantageous environmental stresses and consumer tolerance levels that allow for maximum therapeutic benefit and sensory satisfaction. Future research should focus on the human bioavailability of related compounds in addition to other metabolic factors that effect a therapeutic benefit, including phytochemical interaction with other bioactive compounds. The relationship between PERM cellular homeostasis and sirtuin activation would also aid in the understanding of aging and longevity factors. Long-term human clinical trials including non-obese, healthy subjects would replicate xenohormesis in a controlled environment and provide valuable insight into the potential of its medicinal applications, both preventative and curative. Consolidating current research will establish the need for agricultural and food supply chain practices that ensure evolutionary processes are preserved or encouraged.

\section{Conclusions}

The xenohormesis hypothesis of plant stress and secondary resistance by sirtuin activation and cellular homeostasis mechanisms not only provides a rational explanation for the diverse therapeutic activity of phytochemicals, but also offers an avenue for realistic health intervention. In a time where excessive and inappropriate food consumption has led to an increase in chronic health conditions and reduced lifespan, understanding and applying evolutionary principles to nutritional medicine is a novel, yet promising, concept. Other contemporary factors, including the way we produce and source food, pose a significant threat to evolutionary and/or adaptive processes, and should be considered in relation to contemporary health concerns. Research regarding xenohormetic compounds has produced conflicting results regarding dosage and metabolic activity. Despite confusion, the nutritional and medicinal potential of plant polyphenols represents an area of research likely to produce alternative therapeutic models in the future.

\section{Conflict of interest}

The authors have no conflict of interests related to this publication.

\section{Author contributions}

Idea researched and developed (SS, ML), article crafted in final form (SS, ML).

\section{References}

[1] Mattson MP. Hormesis defined. Ageing Res Rev 2008;7(1):1-7. doi:10.1016/j.arr.2007.08.007.

[2] Baur JA, Sinclair DA. What is Xenohormesis? Am J Pharmacol Toxicol 2008;3(1):152-159. doi:10.3844/ajptsp.2008.152.159.

[3] Howitz KT, Sinclar DA. Xenohormesis: Sensing the chemical cues of other species. Cell 2008;133(3):387-391. doi:10.1016/j. cell.2008.04.019.

[4] Leonov A, Arlia-Ciommo A, Piano A, Svistkova V, Lutchman V, Medkour $\mathrm{Y}$, et al. Longevity extension by phytochemicals. Molecules 2015;20(4):6544-6572. doi:10.3390/molecules20046544.

[5] Yun AJ, Doux JD. Unhappy meal: How our need to detect stress may have shaped our preference for taste. Medical Hypothesis 2007;69(4):7746-7751. doi:10.1016/j.mehy.2007.02.007.

[6] Larsen CS. Animal source foods and human health during evolution. J Nutr 2003;133(11):3893S-3897S.

[7] Etemadi A, Sinha R, Ward MH, Graubard BI, Inoue-Choi M, Dawsey $\mathrm{SM}$, et al. Mortality from different causes associated with meat, heme iron, nitrates, and nitrites in the NIH-AARP Diet and Health Study: Population based cohort study. BMJ 2017;357:j1957. doi:10.1136/ bmj.j1957.

[8] Stanhope KL. Sugar consumption, metabolic disease and obesity: 
the state of the controversy. Crit Rev Clin Lab Sci 2016;53(1):52-67. doi:10.3109/10408363.2015.1084990.

[9] Lim SS, Vos T, Flaxman AD, Danaei G, Shibuya K, Adair-Rohani H, et al. A comparative risk assessment of burden of disease and injury attributable to 67 risk factors and risk factor clusters in 21 regions, 1990-2010: a systematic analysis for the global burden of disease study 2010. Lancet 2012;380(9859):2224-2260. doi:10.1016/s01406736(12)61766-8.

[10] McCay CM, Crowell MF, Maynard LA. The effect of retarded growth upon the length of life span and upon the ultimate body size. 1935. Nutrition 1989;5(3):155-171.

[11] Colman RJ, Beasley TM, Kemnitz JW, Johnson SC, Weidruch R, Anderson RM. Caloric restriction reduces age-related and all-cause mortality in rhesus monkeys. Nat Commun 2014;(5):3557. doi:10.1038/ ncomms4557.

[12] Carmona JJ, Michan S. Biology of Healthy Aging and Longevity. Rev Invest Clin 2016;68(1):7-16.

[13] Lopez-Lluch G, Navas P. Calorie restriction as an intervention in ageing. J Physiol 2016;594(8):2043-2060. doi:10.1113/JP270543.

[14] Testa G, Biasi F, Poli G, Chiarpotto E. Calorie restriction and dietary restriction mimetics: a strategy for improving healthy aging and longevity. Curr Pharm Des 2014;20(18):2950-2977. doi:10.2174/13816 128113196660699.

[15] Joseph SV, Edirisinghe I, Burton-Freeman BM. Fruit polyphenols: A review of anti-inflammatory effects in humans. Crit Rev Food Sci Nutr 2016;56(3):419-444. doi:10.1080/10408398.2013.767221.

[16] Ivey KL, Hodgson JM, Croft KD, Lewis JR, Prince RL. Flavonoid intake and all-cause mortality. Am J Clin Nutr 2015;101(5):1012-1020. doi:10.3945/ajcn.113.073106.

[17] Howitz KT, Bitterman KJ, Cohen HY, Lamming DW, Lavu S, Wood JG, et al. Small molecule activators of sirtuins extend saccharomyces cervisiae lifespan. Nature 2003;425(6954):191-196. doi:10.1038/ nature01960.

[18] Chang HC, Guarente L. SIRT1 and other sirtuins in metabolism. Trends Endocrinol Metab 2014;25(3):138-145. doi:10.1016/j. tem.2013.12.001.

[19] Bavaresco L, Lucini L, Busconi M, Flamini R, De Rosso M. Wine resveratrol: From the gound up. Nutrients 2016;8(4):222. doi:10.3390/ nu8040222.

[20] Wasik A, Antkiewicz-Michaluk L. The mechanism of neuroprotective action of natural compounds. Pharmacol Rep 2017;69(5):851-860. doi:10.1016/j.pharep.2017.03.018.

[21] Caruana M, Cauchi R, Vassallo N. Putative role of red wine polyphenols against brain pathology in Alzheimer's and Parkinson's disease. Nutr 2016;3:31. doi:10.3389/fnut.2016.00031.

[22] Carter LG, D’Orazio JA, Pearson KJ. Resveratrol and cancer: Focus on in vivo evidence. Endocr Relat Cancer 2014;21(3):R209-R225. doi:10.1530/ERC-13-0171.

[23] Bonnefont-Rousselot D. Resveratrol and cardiovascular diseases. Nutrients 2016;8(5):250. doi:10.3390/nu8050250.

[24] Chirumbolo S, Bjorklund G. PERM hypothesis: The fundamental machinery able to elucidate the role of xenobiotics and hormesis in cell survival and homeostasis. Int J Mol Sci 2017;18(1):165. doi:10.3390/ ijms18010165.

[25] Brieger K, Schiavone S, Miller FJ Jr, Krause KH. Reactive oxygen species: From health to disease. Swiss Med Wkly 2012;142:w13659. doi:10.4414/smw.2012.13659.

[26] Xu C, Bailly-Maitre B, Reed JC. Endoplasmic reticulum stress: Cell life and death decisions. J Clin Invest 2005;115(10):2656-2664. doi:10.1172/JCl26373.

[27] Walter $P$, Ron D. The unfolded protein response: from stress pathway to homeostatic regulation. Science 2011;334(6059):1081-1086. doi:10.1126/science.1209038.

[28] Haynes CM, Ron D. The mitochondrial UPR - protecting organelle protein homeostasis. J Cell Sci 2010;123(pt 22):3849-3855. doi:10.1242/jcs.075119.

[29] Hu F, Liu F. Mitochondrial stress: a bridge between mitochondrial dysfunction and metabolic diseases? J Cell Sig 2011;23(10):15281533. doi:10.1016/jcellsig.2011.05.008.

[30] Kim JA, Wei Y, Sowers JR. Role of mitochondria dysfunction in insulin resistance. Circ Res 2008;102(4):401-414. doi:10.1161/CIRCRESA-
HA.107.165472.

[31] Bravo R, Parra V, Gatica D, Rodriguez AE, Torrealba N, Paredes F, et al. Endoplasmic reticulum and the unfolded protein response: dynamics and metabolic integration. Int Rev Cell Mol Biol 2013;301:215-290. doi:10.1016/B978-0-12-407704-1.00005-1.

[32] Bhakta-Guha D, Efferth T. Hormesis: Decoding two sides of the same coin. Pharmaceuticals 2015;8(4):865-883. doi:10.3390/ph8040865.

[33] Wang FM, Ouyan HJ. Regulation of unfolded protein response modulator XBP1s by acetylation and deacetylation. Biochem J 2011;433(1):245-252. doi:10.1042/BJ20101293.

[34] Dangour AL, Dodhia SK, Hayter A, Allen E, Lock K, Uauy R. Nutritional quality of organic foods: a systemic review. Am J Clin Nutr 2009;90(3):680-685. doi:10.3945/ajcn.2009.28041.

[35] Rembialkowska E. Quality of plant products from organic agriculture. JSFA 2007;87(15):2757-2762. doi:10.1002/jsfa.3000.

[36] Lairon D. Nutritional quality and safety of organic food. A review. Agronomy 2010;30(1):33-41. doi:10.1051/agro/2009019.

[37] Hooper PL, Hooper PL, Tytell M, Vigh L. Xenohormesis: Health Benefits from an Eon of Plant Stress Response Evolution. Cell Stress Chaperones 2010;15(6):761-770. doi:10.1007/s12192-010-0206-x.

[38] Oh MM, Carey EE, Rajashekar CB. Environmental stresses induce health-promoting phytochemicals in lettuce. Plant Physiol Biochem 2009;47(7):578-583. doi:10.1016/j.plaphy/2009.02.008.

[39] Schonhof I, Klaring HP, Krumbein A, Clausen W, Schreiner M. Effect of temperature increase under low radiation conditions on phytochemicals and ascorbic acid in greenhouse grown broccoli. Agric, Ecosyst Environ 2007;119(1-2):103-111. doi:10.1016/j.agee/2006/06.018.

[40] Drewnoswki A, Gomez-Carneros C. Bitter taste, phytonutrients, and the consumer: a review. Am J Clin Nutr 2000;72(6):1424-1435.

[41] Francis D, Finer JJ, Grotewold E. Challenges and opportunities for improving food quality and nutrition through plant biotechnology. Curr Opin Biotechnol 2017;44:124-129. doi:10.1016/j.copbio.2016.11.009

[42] Hefferon KL. Nutritionally enhanced food crops; progress and perspectives. Int J Mol Sci 2015;16(2):3895-3914. doi:10.3390/ ijms16023895.

[43] Marues FZ, Markus MA, Morris BJ. Resveratrol: Cellular actions of a potent natural chemical that confers a diversity of health benefits. Int J Biochem Cell Biol 2009;41(11):2125-2128. doi:10.1016/j.biocel.2009.06.003.

[44] Cicero AFG, Colletti A. Role of phytochemicals in the management of metabolic syndrome. Phytomedicine 2016;23(11):1134-1144. doi:10.1016/j.phymed.2015.11.009.

[45] Singh CK, Ndiaye MA, Ahmad N. Resveratrol and cancer: Challenges for clinical translation. Biochem Biophys Acta 2015;1852(6):11781185. doi:10.1016/j.bbadis.2014.11.004.

[46] Espin JC, Garcia-Conesa MT, Thomas-Barberan FA. Nutraceuticals: Facts and fiction. Phytochemistry 2007;68(22-24):2986-3008. doi:10.1016/j.phytochem.2007.09.014.

[47] Bahadoran Z, Tohidi M, Nazeri P, Mehran M, Azizi F, Mirmiran P. Effect of broccoli sprouts on insulin resistance in type 2 diabetic patients: a randomised double-blind clinical trial. Int J Food Sci Nutr 2012;63(7):767-771. doi:10.3109/09637486.2012.665043.

[48] Bai Y, Wang x, Zhao S, Ma C, Cui J, Zheng Y. Sulforaphane protectsagainst cardiovascular disease via NrF2 activation. Oxid Med Cell Longev 2015;(2015):407580. doi:10.1155/2015/407580.

[49] Nagao T, Komine Y, Soga S, Meguro S, Hase T, Tanaka Y, et al. Ingestion of a tea rich in catechins leads to a reduction in body fat and malondialdehyde-modified LDL in men. Am J Clin Nutr 2005;81(1):122-129.

[50] Sanchez-Ramirez I, Taub PR, Ciaraldi TP, Nogueira L, Coe T, Perkins $\mathrm{G}$, et al. (-)-Epicatechin rich cocoa mediated modulation of oxidative stress regulators in skeletal muscle of heart failure and type 2 diabetes patients. Int J Cardiol 2013;168(4):3982-3990. doi:10.1016/j. ijcard.2013.06.089.

[51] Chuengsamarn S, Suthee Rattanamongkolgu S, Luechapudiporn R, Phisalaphong C, Jirawatnotai S. Curcumin extract for prevention of type 2 diabetes. Diabetes Care 2012;35(11):2121-2127. doi:10.2337/ dc12-0116.

[52] Yang YS, Su YF, Yang HW, Lee YH, Chou JI, Ueng KC. Lipid-lowering effects of curcumin in patients with metabolic syndrome: a randomised, double-blind, placebo-controlled trial. Phytother Res 
2014;28(12):1770-1777. doi:10.1002/ptr.5197.

[53] Goh KP, Lee HY, Lau DP, Supaat W, Chan YH, Koh AF. Effects of resveratrol in patients with type 2 diabetes mellitus on skeletal muscle SIRT1 expression and energy expenditure. Int J Sport Nutr Exerc Metab 2014;24(1):2-13. doi:10.1123/ijsnem.2013.0045.

[54] Dash S, Xiao C, Morgantini C, Szeto L, Lewis GF. High-dose resveratrol treatment for 2 weeks inhibits intestinal and hepatic lipoprotein production in overweight/obese men. Arterioscler Thromb Vasc Biol 2013;33(12):2895-2901. doi:10.1161/ATVBAHA.113.302342.

[55] Almerio RU, Karakas SE. Lignan content of the flaxseed influences its biological effects in health men and women. J Am Coll Nutr 2013;32(3):194-199. doi:10.1080/07315724.2013.791147.

[56] Rodrigues-Leyva D, Weighhell W, Edel AL, LaVallee R, Dibrov E, Pinneker $\mathrm{R}$, et al. Potent antihypertensive action of dietary flaxseed in hypertensive patients. Hypertension 2013;62(6):1081-1089. doi:10.1161/HYPERTENSIONAHA.11302094.

[57] Wilson T, Luebke JL, Morcomb EF, Carrell EJ, Leveranz MC, Kobs L, et al. Glycemic responses to sweetened dried and raw cranberries in humans with type 2 diabetes. J Food Sci 2010;75(8):H218-223. doi:10.1111/j.1750-3841.2010.01800.x.

[58] Biesinger S, Michaels HA, Quadros AS, Qian Y, Rabosvsky AB, Badger $\mathrm{RS}$, et al. A combination of isolated phytochemicals and botanical extracts lowers diastolic blood pressure in a randomised controlled trial of hypertensive subjects. Eur J Clin Nutr 2016;70(1):10-16. doi:10.1038/ejcn.2015.88.

[59] Xiao JB, Hogger P. Dietary polyphenols and type 2 diabetes: Current insights and future perspectives. Curr Med Chem 2015;22(1):23-38. doi:10.2174/0929867321666140706130807.

[60] Baur JA, Pearson KJ, Price NL, Jamieson HA, Lerin C, Kalra A, et al. Resveratrol improves health and survival of mice in a high-calorie diet. Nature 2006;444(117):337-342. doi:10.1038/nature05354.

[61] Bullar KS, Hubbard BP. Lifespand and healthspan extension by resveratrol. Biochemica et Biophysica Acta 2015;1852(6):1209-1218. doi:10.1016/j.bbadis.2015.01.012.

[62] Wang C, Wheeler CT, Alberico T, Sun X, Seeberger J, Laslo M, et al. The effect of resveratrol on lifespan depends on both gender and dietary nutrient composition in Drosophila melanogaster. Age (Dordr) 2013;35(1):69-81. doi:10.1007/s11357-011-9332-3.

[63] Witte AV, Kerti L, Margulies DS, Floel A. Effects of resveratrol on memory performance, hippocampal functional connectivity, and glucose metabolism in healthy older adults. J Neurosci 2014;34(23):78627870. doi:10.1523/JNEUROSCI.0385-14.2014.

[64] Timmers S, Koning E, Bilet L, Houtkooper RH, van de Weijer T, Goossens $\mathrm{GH}$, et al. Calorie restriction-like effects of 30 days of resveratrol supplementation on energy metabolism and metabolic profile in obese humans. Cell Metab 2011;14(5):612-622. doi:10.1016/j. cmet.2011.10.002.

[65] Woerdeman J, Del Rio D, Calani L, Smulders YM, Serne EH. Red wine polyphenols do not improve obesity associated insulin-resistance: a randomized controlled trial. Diabetes Obes Metab 2017. doi:10.1111/dom.13044

[66] Yoshino J, Conte C, Fontana L, Mittendorfer B, Imai S, Schechtman KB, et al. Resveratrol supplementation does not improve metabolic function in nonobese women with normal glucose tolerance. Cell Metab 2012;16(5):658-664. doi:10.1016/j.cmet.2012.09.015.

[67] Pagliaro B, Santolamazza C, Simonelli F, Speranca R. Phytochemical compounds and protection from cardiovascular diseases: a state of the art. Biomed Res Int 2015;(2015):918069. doi:10.1155/2015/918069.

[68] Anuzzi G, Bozzetto L, Costabile G, Giacco R, Mangione A, Anniballi G, et al. Diets naturally rich in polyphenols improve fasting and postprandial dyslipidemia and reduce oxidative stress: a randomised controlled trial. Am J Clin Nut 2014;99(3):463-471. doi:10.3945/ ajcn.113.073445.

[69] Tresserra-Rimbau A, Rimm EB, Medina-Remon A, Martinez-Gonzalez MA, Carmen M. Polyphenol intake and mortality risk: a re-analysis of the PREDIMED trial. BMC Med 2014;12:77. doi:10.1186/1741-701512-77.

[70] Hodgson JM, Croft KD, Woodman RJ, Puddey IB, Bondonno CP, Wu JH, et al. Effects of vitamin $\mathrm{E}$, vitamin $\mathrm{C}$ and polyphenols on the rate of blood pressure variation: results of two randomised controlled traisl. B J Nutr 2014;112(9):1551-1561. doi:10.1017/S0007114514002542.

[71] Khurana S, Venataraman K, Hollingsworth A, Piche M, Tai TC. Polyphenols: Benefits to the cardiovascular system in health and in aging. Nutrients 2013;5(10):3779-3827. doi:10.3390/nu5103779.

[72] Tangney C, Rasmussen HE. Polyphenols, inflammation and cardiovascular disease. Curr Atheroscler Rep 2013;15(5):324. doi:10.1007/ s11883-013-0324-x.

[73] Zamora-Ros R, Andres-Lacueva C, Lamuela-Raventós RM, Berenguer T, Jakszyn P, Martínez C, et al. Concentrations of resveratrol and derivatives in foods and estimation of dietary intake in a Spanish population: European prospective investigation into cancer and nutrition (EPIC)-spain cohort. B J Nutr 2008;100(1):188-196. doi:10.1017/ S0007114507882997.

[74] Hu P, Zhao L, Chen J. Physiologically achievable doses of resveratrol enhance 3T3-L1 adipocyte differentiation. Eur J Nutr 2015;54(5):569579. doi:10.1007/s00394-014-0738-4.

[75] Scott E, Cai H, Kholghi A, Andradi C, Rufini A. Less is more for cancer chemoprevention: evidence of a non-linear dose response for the protective effects of resveratrol in humans and mice. Sci Transl Med 2015;7(298):298ra117. doi:10.1126/scitransImed.aaa7619. 